\title{
Growth Trajectories of Task Value and Self-efficacy Across an Academic Semester
}

\author{
Marcus Lee Johnson ${ }^{1, *}$, Ordene V. Edwards ${ }^{2}$, Ting Dai ${ }^{3}$ \\ ${ }^{1}$ Developmental and Learning Sciences Research Center, University of Cincinnati, Cincinnati, 45221-0105, Ohio, United States \\ ${ }^{2}$ Lamar University, 400 South M L King Junior Parkway, Beaumont, 77705, Texas, United States \\ ${ }^{3}$ Department of Psychological, Organizational and Leadership Studies in Education, Temple University, 2129 North Broad Street, \\ Philadelphia, 19122, Pennsylvania, United States \\ *Corresponding Author: Marcus.Johnson@uc.edu
}

Copyright (C) 2014 Horizon Research Publishing All rights reserved.

\begin{abstract}
Many scholars have argued that motivation is dynamic and malleable across time and contexts. In this article, we investigated changes in undergraduates' task value and self-efficacy across an academic semester. Sixty three undergraduate students completed the Motivated Strategies for Learning Questionnaire across five time points in their introductory educational psychology class. We predicted that, across the semester, students' expressiveness of these constructs would change. Using growth curve modeling, we found both constructs to fluctuate in a cubic fashion. The implications of these findings are discussed.
\end{abstract}

Keywords Task Value, Self-Efficacy, Growth Curve

\section{Introduction}

This research examined the patterns of change of college students' task value and self-efficacy across an academic semester. Several prior studies have examined changes in motivational constructs and have typically found that students' motivation shifts across time and/or contexts. Particularly, these studies have documented changes in motivation from one grade level to the next [1-4]; within a school year [5]; across a semester [6-8]; across developmental levels [9]; and as a function of various tasks $[10,11]$.

Changes in task value and self-efficacy over time and across varied academic settings have been reported $[2,4,5$, $8]$. These findings support the expectancy-value theory of motivation, which postulates that individuals' values and expectancy beliefs change across time $[12,13]$. That is, as people develop, their abilities, values, and efficacy beliefs may change as they reflect upon their experiences with successes and failures.

Although previous research has confirmed the malleability of task value and self-efficacy, little is known about the patterns of these changes. To our knowledge, it is not known whether motivational shifts are gradual or dramatic, nor whether they are steep at the beginning, middle, or end of the academic term. In this paper, we investigate patterns of motivational change by assessing the growth and declines of task values and self-efficacy five times across an academic semester.

Investigating the patterns of change in motivational mechanisms may help inform educators and researchers about optimal times in which motivational interventions can be employed; and how the motivational mechanisms may interact (or change together). Many educators may in fact find it encouraging that students' motivation can change, and that they may be able to do something to facilitate that change for the better.

\subsection{Motivational Change}

Current research findings suggest that motivational constructs do change over time and/or contexts. Specifically, in transition settings, Otis [3] found decreases in intrinsic and extrinsic motivation from the junior to senior high school years. Similarly, Shim [4] and Caprara [2] found overall declines in mastery and performance goal orientations and self-efficacy for students transitioning from middle school to high school. Changes have also been reported for transitions within the lower grades. For instance, Wang [14] found that students' performance and mastery goals generally declined from $7^{\text {th }}$ to $8^{\text {th }}$ grade. In contrast, Anderman [1] found increases in the mastery goal and declines in the performance goal among students transitioning from elementary to middle school.

Existing evidence also illustrates that motivational constructs may shift within a school year. For example, Bong [5] found that self-efficacy and mastery goals increased from the beginning to the end of the year among Korean high school girls. In contrast, Chouinard [15] found that mastery goals tend to be lower at the end of the school year than at the beginning, for secondary school aged students enrolled in mathematics. Motivational shifts have also accompanied 
changes in development. For instance, Corpus [9] found that intrinsic and extrinsic motivation generally decreased from childhood to adolescence.

Moreover, motivational changes have been documented across an academic semester. For instance, Zusho [8] reported motivational declines for task value, self-efficacy, and mastery and performance goals in undergraduate chemistry students across an academic semester. Senko [6] found that in an academic semester, college students repeatedly switched between performance-avoidance and performance-approach goals and decreased their endorsements of the mastery goal. Similarly, Winne [7] found that students' mastery-approach, performance-approach, and performance-avoidance goals declined over the course of a semester, however, their mastery-avoidance goal increased over time. Researchers have also examined changes in motivation across various tasks in an academic semester. For example, Muis and Edwards [11] and Fryer [10] examined changes in achievement goal orientations across various tasks in a 15 -week semester. Results demonstrated patterns of both change and stability across goals.

\subsection{Expectancy-Value Theory (EVT)}

Of the many theories of motivation that provide rationales for change [10], Eccles' [16] model of Expectancy-Value Theory (EVT) is unique in that they present a cyclical framework that illustrates that motivational changes are ongoing with every achievement experience. Eccles's [16] cyclical EVT model explicitly recognizes that a learner will reevaluate their motivation for a task in accordance with their gains in experience. Success or failure on a task may influence a learner's affective reactions/memories of the task which can then result in changes to the learner's interactions with subsequent/similar tasks (i.e. how they value the task, how they identify with the task, and/or how they interpret their possible future performances/outcomes with the task).

Conceived in the first half of the twentieth century, EVT postulates that individuals are motivated for a task when they value the task and/or expect that they will do well in the task [17]. Though this underlying premise remains relatively unchanged, contemporary expectancy-value models are regarded as social cognitive frameworks of motivation, assumed to influence and be influenced by social and cognitive processes [18]. The two major components of expectancy-value theory are task values and expectancies, where task values are defined as the reasons individuals engage in a task and expectancies are defined as judgments people make about obtaining desirable outcomes on a task [12].

Presently, there is a four-construct framework of task value [12]: utility values, attainment values, intrinsic values, and cost values. A motivated individual may perceive a high utility value for tasks they find useful or relevant to their current and/or future experiences; a high attainment value for tasks they believe may confirm salient issues of their self-schema (i.e. identifying oneself as an athlete and pursuing activities that prioritize athletic abilities); a high intrinsic value for tasks they believe are interesting and/or exciting; or a high cost value for tasks they feel obligated to participate in or perceive may have negative consequences should they not engage in the task.

A dichotomous framework of expectancy beliefs, which differentiates between efficacy expectations and outcome expectations, has been proposed [18]. Efficacy expectations are beliefs about one's capability to do well on a task; and outcome expectations are beliefs of being awarded the desirable outcomes [16]. An example that may illustrate the differences between the two expectancy beliefs is a student who wants a letter grade of " $\mathrm{A}$ " in a math course. If the student assumes that the class is an easy class that everyone can pass, they may have a high outcome expectation that they will be awarded an "A" without much effort. If the student however assumes the class is challenging, but confident in their ability to master the content, they may have a high efficacy expectation and put forth effort to obtain an "A." Bandura [19] may characterize the student in the latter example, as being efficacious or having high self-efficacy in their ability to obtain a desirable outcome.

Previous motivational research suggests that self-efficacy is one of the strongest predictors of academic achievement $[20,21]{ }^{1}$ Task value is also predictive of academic effort and subsequent achievement [22]. Therefore, one expects that a learner who is high in both task value and self-efficacy may experience optimal learning. However, an early postulation of the expectancy-value model hypothesized an inverse relationship between expectancies and task values, suggesting that as one's expectations to be successful increase, the less [incentive] value is needed to be motivated [23].

Many motivation scholars today do not subscribe to this early hypothesis, and instead are supportive of the evidence that expectancies and values are positively related $[8,16,24$, 25]. If a learner becomes anxious about their ability to obtain desirable outcomes (expectancy) on a task, they may simultaneously devalue the task to protect their self-worth [26]; and vice versa. Particularly, Bong [21] found that self-efficacy and task value were positively related across middle school and high school, and across subject domains. Similarly, Zusho [8]) found that task value and self-efficacy were positively related across three time points during an academic term for college chemistry students. With the exception of high achieving learners, changes of task value and self-efficacy for low and medium achieving students moved in the same downward direction. Given the strong positive relationship, one could hypothesize that if self-efficacy changes, a similar change may be observed in task value and vice versa.

\subsection{Purpose of the Present Study}

1 For this study we measured self-efficacy to represent the efficacy expectation component of EVT. 
The purpose of the current study was to examine the patterns of change in task value and self-efficacy across five time points in a semester. Whereas Bong [5] collected data at four time points for self-efficacy, we collected five waves of data for both task value and self-efficacy. The five data points provide the opportunity to more thoroughly investigate patterns of change to the trajectories of task value and self-efficacy. In our review, most studies examining the malleability of task value and self-efficacy only investigated mean level changes across time points and not the pattern of these changes. We ask how do students' task value and self-efficacy in an undergraduate course change over a semester? Based on previous research $[5,8]$, we hypothesize that fluctuations should be observed for task value and self-efficacy. Specifically, with five time points, our investigation can go beyond investigating linear trends; and allow us to investigate whether task value and self-efficacy fit cubic trajectories, which is what we expect to find since we hypothesize fluctuations. Also, we will investigate the shape of the trajectories for both task value and self-efficacy, expecting for task value and self-efficacy to generally move in similar directions and identifying when and the degree to which changes take place.

\section{Materials and Methods}

\subsection{Participants}

Sixty-three undergraduates enrolled in an introductory educational psychology course at a large university in the Southwestern region of the United States, participated in this study. Forty-seven were females and 16 were males. The combined mean age of the students was 21.78 years old (SD $=4.16$ ) with a range of 18 to 43 years. The mean self-reported GPA was $3.23(\mathrm{SD}=.42)$. Freshmen made up $3.2 \%$ of the sample, sophomores $38.1 \%$, juniors $44.4 \%$, and seniors $14.3 \%$. The characteristics of this sample were consistent across other course sections of this educational psychology course at this institution from which our sample was obtained. Also, the timing and general structure for course sections were consistent in terms of having two course assignments and two exams.

\subsection{Measures}

\subsubsection{Motivated Strategies for Learning Questionnaire}

Items were taken from the Motivated Strategies for Learning Questionnaire (MSLQ) [27] to assess students' task value and self-efficacy. Students were participating in a multifaceted study and responded to all items on the MSLQ. The task value and self-efficacy scales are 2 of 9 non-overlapping motivation subscales of the MSLQ. Self efficacy comprises of 8 items and the task value scale consists of 6 items. $^{2}$ Participants indicated their response to

2 Though we acknowledge earlier in this paper that Eccles [16] defined four each item on a 7 point scale ranging from 1 (not at all true of me) to 7 (very true of me). The MSLQ is a well-established measure with strong reported reliability and validity [27, 28]. Both measures demonstrated acceptable reliability at all five time points, ranging from .63 to .94 (see Table 1).

Items for the self-efficacy subscale included 'I'm certain I can understand the most difficult material presented in the readings for this course." Items for the task value subscale included "I think I will be able to use what I learn in this course in other courses." To minimize any order effects, items were randomized for the second, third, fourth, and fifth administrations of the MSLQ.

Table 1. Self-efficacy and task value measure reliability.

\begin{tabular}{|c|c|c|c|c|c|}
\hline & & \multicolumn{2}{|c|}{ Task-Value } & \multicolumn{2}{c|}{ Self-Efficacy } \\
\hline & Time in Semester & $\begin{array}{c}\text { Cronbach's } \\
\text { alpha }\end{array}$ & $N$ & $\begin{array}{c}\text { Cronbach's } \\
\text { alpha }\end{array}$ & $N$ \\
\hline 1 & $\begin{array}{c}\text { Beginning of } \\
\text { Semester }\end{array}$ & .854 & 62 & .888 & 61 \\
\hline 2 & $\begin{array}{c}\text { Before } \\
\text { Assignment 1 }\end{array}$ & .760 & 61 & .895 & 60 \\
\hline 3 & Before Exam 1 & .690 & 63 & .692 & 61 \\
\hline 4 & $\begin{array}{c}\text { Before } \\
\text { Assignment 2 }\end{array}$ & .643 & 62 & .634 & 63 \\
\hline 5 & Before Exam 2 & .939 & 60 & .918 & 60 \\
\hline
\end{tabular}

\subsection{Procedure}

Participants completed the MSLQ five times throughout a 15-week academic semester. Approximately 1 week into the semester, before any assessments were assigned, participants were asked to complete the MSLQ. Participants again completed the instrument before their first assignment $\left(3^{\text {rd }}\right.$ week of the semester), before their first exam ( $6^{\text {th }}$ week), before their second assignment $\left(11^{\text {th }}\right.$ week) and before the final exam (14 ${ }^{\text {th }}$ week). Participants completed a demographic questionnaire in the beginning of the semester.

\subsection{Data Analysis}

To assess the growth patterns for the two constructs of interest, we modeled the changes in self-efficacy and task value each in latent growth curve models (LGM) with the five-wave data during the semester (i.e., Weeks 1, 3, 6, 11, and 14). LGMs parameterize times via the factor loadings that relate the repeated measures (i.e., the manifest variables) to the latent factors representing the growth terms (Byrne, 2012). The means of the latent intercept indicates the initial level of scores, and latent means of slope, quadratic, and cubic terms represent the rate of change over time. We chose LGM over repeated-measures ANOVA due to the statistical power advantages of LGM in detecting growth over time [30].

We analyzed the one-semester growths of task value and

task values, the MSLQ does not provide enough items to isolate the four task values individually. Instead the task value subscale has been used as an additive scale for general task value. 
self-efficacy in three sets of growth models: 1) unconditional linear growth models each with a latent intercept and a latent slope, 2) quadratic-shape growth models each with a quadratic term in addition to the intercept and the slope, and finally 3) cubic-shape growth models each with a cubic-term in addition to the intercept, the slope, and the quadratic term. We hypothesized the cubic LGMs to fit our data adequately and to provide precise and meaningful description of the growth patterns of task value and self-efficacy during the course of a semester since we collected data at five different time points and expected motivational fluctuations.

Data analysis was conducted using Mplus 6.11 [31]. We accounted for missing data in the analyses using Full Information Maximum Likelihood (FIML) [32] as the model estimator. The model fit indices (except Standardized Root Mean Square Residual [SRMR]) were adjusted for the small sample size based on Herzog [33, 34]. The cutoff criteria for adequate model are root-mean-square error of approximation $(\mathrm{RMSEA}) \leq .05$, comparative fit index $(\mathrm{CFI}) \geq .95$, Tucker-Lewis Index $(\mathrm{TLI}) \geq .95, \mathrm{SRMR} \leq .08$ [34-36].

\section{Results}

\subsection{Preliminary Analyses}

The sum scores of self-efficacy and task value measures were calculated at each of the 5 time points and used as manifest variables for the LGMs of change over time. The descriptive statistics and bivariate correlations are presented in Table 2. The mean scores of the two measures at the five time points implied fluctuations of self-efficacy and task value. The correlations amongst the 5-time scores were all significant for self-efficacy and for task value, respectively.

\subsection{Growth Trajectories of Task Value and Self-Efficacy}

In order to further examine students' task value and self-efficacy from the perspective of change, we modeled the 5 waves of task value and self-efficacy scores each in a series of LGM models. We compared the fit indices of the models to select a growth pattern that fit the data adequately, and obtained the parameter estimates from the best-fitting models to describe the growth patterns of task value and self-efficacy over the course of a semester. The fit indices and model comparisons are presented in Tables $3 \mathrm{a}$ and $3 \mathrm{~b}$. The LGM model parameter estimates and model-explained variances in task value and self-efficacy scores are presented in Table 4.

Table 2. Descriptive statistics \& Pearson correlations of task value and self-efficacy sum scores.

\begin{tabular}{|c|c|c|c|c|c|c|c|c|c|c|c|c|}
\hline & \multicolumn{2}{|c|}{ Descriptives } & \multicolumn{10}{|c|}{ Bivariate Correlation } \\
\hline & Mean $(S D)$ & $N$ & TV1 & TV2 & TV3 & TV4 & TV5 & SE1 & SE2 & SE3 & SE4 & SE5 \\
\hline Task-value 1 & $35.0(4.9)$ & 62 & 1.000 & & & & & & & & & \\
\hline Task-value 2 & $34.0(4.7)$ & 61 & $.708^{* * *}$ & 1.000 & & & & & & & & \\
\hline Task-value 3 & $32.1(5.1)$ & 63 & $.519^{* * *}$ & $.546^{* * *}$ & 1.000 & & & & & & & \\
\hline Task-value 4 & $30.0(4.6)$ & 62 & $.438^{* * *}$ & $.544^{* * *}$ & $.589^{* * *}$ & 1.000 & & & & & & \\
\hline Task-value 5 & $33.7(6.8)$ & 60 & $.612^{* * *}$ & $.603^{* * *}$ & $.514^{* * *}$ & $.668^{* * *}$ & 1.000 & & & & & \\
\hline Self-efficacy 1 & $45.9(6.4)$ & 61 & $.378^{* *}$ & $.354^{* *}$ & $.524^{* * *}$ & $.383^{* *}$ & $.295^{* *}$ & 1.000 & & & & \\
\hline Self-efficacy 2 & $46.7(6.4)$ & 60 & $.292^{* *}$ & $.543^{* * *}$ & $.618^{* * *}$ & $.455^{* * *}$ & $.362^{* *}$ & $.763^{* * *}$ & 1.000 & & & \\
\hline Self-efficacy 3 & $42.7(6.3)$ & 61 & $.280^{* *}$ & $.505^{* * *}$ & $.698^{* * *}$ & $.473^{* * *}$ & $.391^{* * *}$ & $.467^{* * *}$ & $.620^{* * *}$ & 1.000 & & \\
\hline Self-efficacy 4 & $40.7(6.3)$ & 63 & $.479^{* * *}$ & $.567^{* * *}$ & $.746^{* * *}$ & $.736^{* * *}$ & $.659^{* * *}$ & $.383^{* *}$ & $.457^{* * *}$ & $.708^{* * *}$ & 1.000 & \\
\hline Self-efficacy 5 & $43.6(7.7)$ & 60 & $.355^{* *}$ & $.492^{* * *}$ & $.423^{* *}$ & $.656^{* * *}$ & $.720^{* * *}$ & $.498^{* * *}$ & $.536^{* * *}$ & $.492^{* * *}$ & $.663^{* *}$ & 1.000 \\
\hline
\end{tabular}

Note. $N=63$. TV $=$ Task-value. $\mathrm{SE}=$ Self-efficacy. ${ }^{* * *} p<.001 .{ }^{* *} p<.01$.

Table 3a. Model comparison based on chi-square difference test.

\begin{tabular}{|c|c|c|c|c|c|c|}
\hline & Model Description & Chi-square $(p)$ & $d f$ & Target Model & $\Delta$ Chi-square $(p)$ & $\Delta d f$ \\
\hline & Task-Value & & & & & \\
\hline A & Nongrowth model & $96.290(p<.001)$ & 13 & -- & -- & -- \\
\hline $\mathrm{B}$ & Linear model & $63.276(p<.001)$ & 12 & A & $33.014(p<.05)$ & 1 \\
\hline $\mathrm{C}$ & Quadratic model & $50.750(p<.001)$ & 9 & $\mathrm{~B}$ & $12.526(p<.05)$ & 3 \\
\hline \multirow[t]{2}{*}{$\mathrm{D}$} & Cubic model $^{*}$ & $4.753(p=.447)$ & 5 & $\mathrm{C}$ & $45.997(p<.05)$ & 4 \\
\hline & Self-Efficacy & & & & & \\
\hline A & Nongrowth model & $106.714(p<.001)$ & 13 & -- & -- & -- \\
\hline $\mathrm{B}$ & Linear model & $75.771(p<.001)$ & 12 & A & $30.943(p<.05)$ & 1 \\
\hline $\mathrm{C}$ & Quadratic model & $64.125(p<.001)$ & 9 & $\mathrm{~B}$ & $11.646(p<.05)$ & 3 \\
\hline $\mathrm{D}$ & Cubic model $^{*}$ & $5.924(p=.314)$ & 5 & $\mathrm{C}$ & $58.201(p<.05)$ & 4 \\
\hline
\end{tabular}

Note. The model comparisons were conducted with Mplus (6.11) [31] generated chi-square and degrees of freedom. *Best-fitting model. 
Table 3b. Model fit indices for linear, quadratic, and cubic models of growth.

\begin{tabular}{|c|c|c|c|c|c|c|c|}
\hline Model & \# of parameters & Original Fit Indices & \multicolumn{5}{|c|}{ Swain-Corrected Fit Indices } \\
\hline & & SRMR & Chi-square $(d f)$ & RMSEA (CI90\%) & Gamma_1 (CI90\%) & TLI & CFI \\
\hline Nongrowth & & & & & & \\
\hline Task-value & 7 & .433 & $96.290^{* * *}(13)$ & $.319(.261, .380)$ & $.667(.600, .734)$ & .551 & .416 \\
\hline Self-efficacy & 7 & .328 & $106.714^{* * *}(13)$ & $.338(.281, .399)$ & $.643(.579, .707)$ & .542 & .404 \\
\hline Linear & & & & & & \\
\hline Task-value & 8 & .242 & $61.192^{* * *}(12)$ & $.257(.195, .323)$ & $.759(.667, .845)$ & .713 & .655 \\
\hline Self-efficacy & 8 & .179 & $73.276^{* * *}(12)$ & $.287(.226, .352)$ & $.717(.627, .803)$ & .675 & .610 \\
\hline Quadratic & 11 & .243 & $48.916^{* * *}(9)$ & $.267(.197, .343)$ & $.795(.702, .878)$ & .689 & .720 \\
\hline Task-value & 11 & .160 & $61.807^{* * *}(9)$ & $.308(.238, .382)$ & $.746(.658, .823)$ & .627 & .664 \\
\hline Self-efficacy & & & & & & \\
\hline Cubic & 15 & .033 & $4.564(5)$ & $.000(.000, .172)$ & $1.003(.946, .999)$ & 1.000 & 1.000 \\
\hline Task-value & 15 & .079 & $5.689(5)$ & $.0471(.000, .191)$ & $.996(.934, .999)$ & .991 & .996 \\
\hline Self-efficacy & & & & & & & \\
\hline
\end{tabular}

Note. Original fit indices were estimated by Mplus (6.11) [31]. Swain-corrected fit indices are results from Swain-correction with Mplus-estimated fit indices based on Herzog [34]. ${ }^{* * *} p<.001$.

Table 4. Unstandardized parameter estimates of growth models of task value and self-efficacy \& model-explained variances in 5-wave scores.

\begin{tabular}{|c|c|c|c|c|c|c|c|c|}
\hline & \multicolumn{2}{|c|}{ Nongrowth Models } & \multicolumn{2}{|c|}{ Linear Models } & \multicolumn{2}{|c|}{ Quadratic Models } & \multicolumn{2}{|c|}{ Cubic Models } \\
\hline & Task-Value & Self-Efficacy & Task-Value & Self-Efficacy & Task-Value & Self-Efficacy & Task-Value & Self-Efficacy \\
\hline \multicolumn{9}{|l|}{$\begin{array}{c}\text { Fixed Effects } \\
\text { (Latent Means) }\end{array}$} \\
\hline Intercept & $33.439^{* * *}$ & $43.907^{* * *}$ & $34.855^{* * *}$ & $46.153^{* * *}$ & $35.499^{* * *}$ & $46.813^{* * *}$ & $34.872^{* * *}$ & $45.882^{* * *}$ \\
\hline Slope & -- & -- & $-1.149^{* * *}$ & $-1.266^{* * *}$ & $-2.864^{* * *}$ & $-2.940^{* * *}$ & $1.891^{*}$ & $3.895^{* * *}$ \\
\hline Quadratic term & -- & -- & -- & -- & $0.517^{* * *}$ & $0.474^{* *}$ & $-3.079^{* * *}$ & $-4.239^{* * * *}$ \\
\hline Cubic term & -- & -- & -- & -- & -- & -- & $0.630^{* * *}$ & $0.782^{* * *}$ \\
\hline \multicolumn{9}{|l|}{$\begin{array}{c}\text { Random Effects } \\
\text { (Factor Variances) }\end{array}$} \\
\hline Intercept & $14.302^{* * *}$ & $22.914^{* * *}$ & $13.685^{* * *}$ & $22.919^{* * *}$ & $12.397^{* * *}$ & $23.557^{* * *}$ & $18.718^{* * *}$ & $34.490^{* * *}$ \\
\hline Slope & -- & -- & 0 & 0 & 0 & 0 & 0 & 0 \\
\hline Quadratic & -- & -- & -- & -- & 0.015 & $0.086^{*}$ & $1.863^{* *}$ & $4.218^{* * *}$ \\
\hline Cubic & -- & -- & -- & -- & -- & -- & $0.113^{*}$ & $0.240^{* *}$ \\
\hline \multicolumn{9}{|l|}{ Residual Variances } \\
\hline Time 1 Scores & $11.471^{* * *}$ & $23.903^{* * *}$ & $8.926^{* * *}$ & $19.184^{* * *}$ & $9.576^{* * *}$ & $17.823^{* *}$ & $4.929^{*}$ & $7.556^{*}$ \\
\hline Time 2 Scores & $6.814^{* * *}$ & $24.133^{* * *}$ & $6.801^{* * *}$ & $18.612^{* * *}$ & $8.372^{* * *}$ & $19.869^{* * *}$ & $6.951^{* * *}$ & $11.149^{* * *}$ \\
\hline Time 3 Scores & $15.593^{* * *}$ & $17.890^{* * *}$ & $13.205^{* * *}$ & $16.397^{* * *}$ & $12.779^{* * *}$ & $15.513^{* * *}$ & $13.171^{* * *}$ & $11.790^{* * *}$ \\
\hline Time 4 Scores & $26.927^{* * *}$ & $30.227^{* * *}$ & $14.564^{* * *}$ & $22.161^{* * *}$ & $14.168^{* * *}$ & $18.178^{* * *}$ & 4.813 & $7.118^{*}$ \\
\hline Time 5 Scores & $21.761^{* * *}$ & $29.544^{* * *}$ & $33.937^{* * *}$ & $38.264^{* * *}$ & $19.143^{* *}$ & $19.866^{*}$ & 7.695 & 3.374 \\
\hline \multicolumn{9}{|c|}{ Variances Explained } \\
\hline Time 1 Scores & $.555^{* * *}$ & $.489^{* * *}$ & $.605^{* * *}$ & $.544^{* * *}$ & $.436^{* * *}$ & $.431^{* * *}$ & $.792^{* * *}$ & $.820^{* * *}$ \\
\hline Time 2 Scores & $.677^{* * *}$ & $.487^{* * *}$ & $.668^{* * *}$ & $.552^{* * *}$ & $.397^{* * *}$ & $.461^{* * *}$ & $.670^{* * *}$ & $.707^{* * *}$ \\
\hline Time 3 Scores & $.478^{* * *}$ & $.562^{* * *}$ & $.509^{* * *}$ & $.583^{* * *}$ & $.479^{* * *}$ & $.401^{* * *}$ & $.472^{* * * *}$ & $.685^{* * *}$ \\
\hline Time 4 Scores & $.347^{* * *}$ & $.431^{* * *}$ & $.484^{* * *}$ & $.508^{* * *}$ & $.463^{* * *}$ & $.406^{* * *}$ & $.772^{* * *}$ & $.824^{* * *}$ \\
\hline Time 5 Scores & $.397^{* * *}$ & $.437^{* * *}$ & $.287^{* *}$ & $.375^{* *}$ & $.475^{* *}$ & $.304^{* *}$ & $.825^{* * *}$ & $.941^{* * *}$ \\
\hline
\end{tabular}

Note. Slope random effects were set to be 0 for all models. ${ }^{* * *} p<.001 .{ }^{* *} p<.01,{ }^{*} p<.05$ 


\subsubsection{Nongrowth Models}

We first modeled the five-time scores of task value and self-efficacy each in a baseline nongrowth model by specifying only an intercept factor. For both task value and self-efficacy, the nongrowth models fit the data poorly even after correcting the fit indices according to Herzog [33], which suggests that the nongrowth model did not accurately describe the pattern of the scores at five time points and that both task value and self-efficacy changed over the course of a semester.

\subsubsection{Linear Growth Models}

We specified each of the linear models for task value and self-efficacy by setting the slope-factor loadings to be $0,1,2$, 3 , and 4 for Times 1-5, respectively, and the intercept-factor loadings to be 0 for all five paths. We also set the variance of the slope factor to be zero to estimate slope as a fixed effect (i.e., a non-random slope) in each applicable model. For both task value and self-efficacy, the linear models fit the data poorly even after correcting the fit indices according to Herzog [33], which indicated neither task value nor self-efficacy changed in a simple linear pattern over the course of a semester. Model-explained variances in the task value and self-efficacy scores varied for the 5 waves $(28.7 \%$ $\sim 66.8 \%$ ), and for Time- 5 task value and self-efficacy scores the explained variances were especially low $\left(r^{2}=28.7 \%, r^{2}=\right.$ $37.5 \%$, respectively), which indicated that the linear model did not accurately describe the changes for the entire semester. Both model fits and model-explained variances indicated that a nonlinear (i.e., quadratic or cubic) model might describe the growth patterns of task value and self-efficacy more accurately.

\subsubsection{Quadratic Growth Models}

Based on the unconditional linear models, we hypothesized an additional quadratic factor that explained the scores at the five waves, and specified it in the LGM by setting the five quadratic-path loadings to be $0,1,4,9$, and 16, from Times 1 to 5 , respectively. The quadratic models fit the data better than the linear models, however, for both task value and self-efficacy, the quadratic models still did not provide adequate fits even after correcting the fit indices according to Herzog [33]. Neither task value nor self-efficacy changed in a quadratic pattern over the course of a semester. Model-explained variances in the 5-wave task value and self-efficacy scores were all lower than $50 \%$, and, especially for Time-5 self-efficacy scores, there were only $30.4 \%$ of the variances accounted for by the quadratic model.

\subsubsection{Cubic Growth Models}

Based on the quadratic models, we hypothesized an additional cubic factor that explained the scores at the five waves, and specified it in the LGM by setting the five cubic-path loadings to be $0,1,8,27$, and 64 , from Times 1 to 5 , respectively. Compared to the quadratic models, the cubic models fit both task value and self-efficacy data significantly better. The cubic-model fit indices of both task value and self-efficacy models met all the model fit criteria and indicated adequate fit to the data. All latent growth terms (i.e., intercept, slope, quadratic, and cubic terms) were found to have significant means (i.e., fixed effects), which indicated students' task value and self-efficacy each changed in a cubic-shape pattern over the course of a semester. Model-explained variances in the 5-wave task value and self-efficacy scores were all higher than $67 \%$ (except for Time-3 task value $r^{2}=47.2 \%$ ), indicating that the cubic growth models accounted for significant and sufficient amounts of the variances in task value and self-efficacy scores at the five waves.

Both task value and self-efficacy changed across the academic semester and illustrated cubic trajectories (see Figure 1 for prototypical growth curves). The gradual declines and rebound observed for both variables suggest that prior to students' final exams and after receiving feedback on previous exams and assignments, students' internalize the overall value of the course and became more confident about what they need to accomplish to obtain desirable outcomes.

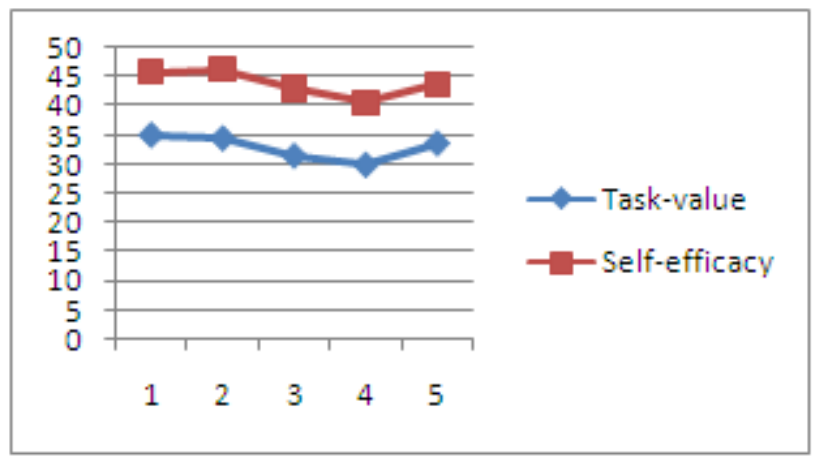

Figure 1. Prototypical growths of task-value and self-efficacy over five time points during a semester.

\section{Discussion}

Increasingly, researchers are calling for studies of change in motivation, rather than treating motivation as a static trait-like factor that influences learning $[1,4]$. The present study was designed to investigate two motivational constructs - task value and self-efficacy-in terms of whether they change and how they change throughout the course of a semester. Our findings from the latent growth curve model comparisons support that task value and self-efficacy do change over the course of a semester, and that the changes are not merely a linear decrease or increase throughout the semester but in a cubic pattern with a minor increase at the beginning, greater decline in the mid-semester and a general increase at the end of the semester.

We believe these findings contribute to our understanding of how task value and self-efficacy may change. Specifically, we believe our findings support Eccles' [16] model of expectancy-value theory in that the fluctuations we observe 
provide evidence that learners may constantly reevaluate their motivations (i.e. self-efficacy and task value) as they experience success and failures. Due to the cubic trajectories we observed, we can report that motivational declines are not always inevitable and we believe that having collected five waves of data allowed us to identify cubic trajectories, for which three or four time points could not. Additionally, with both task value and self-efficacy having cubic trajectories we provide further evidence that the two constructs may be more compatible $[16,37]$ than they are inversely related.

Figure 1 illustrates that both task value and self-efficacy begin to decrease after students' first assignment and approach their lowest points just before their second assignment. This suggests that should educators in similar courses wish to employ motivational interventions, that they consider implementing such interventions mid-term. We found that task value and self-efficacy appear to rebound to almost their initial levels toward the end of the semester and ponder what mechanisms trigger this rebound. We speculate that students in our sample grew in their efficacy between assignment 2 and exam 2 because the feedback they may have received from all previous assessments enhanced their confidence and what to expect in the final exam. With increased efficacy, students may too perceive higher task value since self-efficacy may enhance one's sense of self-worth. Additionally, knowing that the second and final exam is likely to be perceived by students as the culminating assessment that may solidify their final desired grade, it may not be too surprising that students' task value had increased at the time the second exam was approaching.

\subsection{Limitations and Future Directions}

It is important to keep in mind a few limitations when interpreting the findings of the current study. First, the sample size is relatively small, which may potentially limit generalization to larger college student populations. However, the study was done within a naturalistic setting over the course of a semester adding more ecological validity to the findings. Future researchers could do well in replicating the study with larger sample sizes which may allow for modeling task value and self-efficacy together. Future research could also use different populations of students in varying contexts to determine whether cubic trajectories for task value and self-efficacy are commonplace. ${ }^{3}$

Second, we acknowledge the limitations of using self-report measures. Particularly, the use of self report limits a broader understanding of the malleability of task value and self-efficacy. Therefore, we urge future researchers to utilize other methods of measurement to understand the nature of change and stability of these variables.

Third, we did not examine the role of feedback on task

3 Our results may have been contingent upon the context and structure of the course from which we obtained our sample. Meaning, participants' attitudes may have been influenced by the timing of course assignments and exams. Therefore, future research may consider utilizing student samples from courses with differing structures. value and self efficacy changes nor did we control for it. Senko [6] and [7] found that feedback may indeed influence motivational change. It is plausible that changes observed in the current study may have been influenced by evaluative feedback. Future researchers may examine the role of feedback on patterns of change in task value and self efficacy over an extended period of time.

\subsection{Conclusions}

Despite the challenges of the current study, our results may have important theoretical, methodological, and practical implications. In regards to the theoretical implications, we believe that our findings are supportive of Eccles' [16] EVT model in that the fluctuations we observe can be interpreted as indicating continuous reassessment of learners' motivation with every achievement experience. Second, current evidence shows that self-efficacy and task value are indeed malleable [8]; adding to the extant literature about the stability of these motivational constructs. Furthermore, the study is innovative in that it explicates the [cubic] patterns of change of task value and self-efficacy over time. These findings are particularly relevant as many theoretical postulations are limited to merely mean level changes of task value and self-efficacy. Our study may provide a better understanding of the patterns of change for task value and self-efficacy. Finally, our findings support the notion that task value and self-efficacy are positively related, as opposed to inversely related consistent with previous studies $[5,8]$.

Methodologically, we believe this study contributes to the literature concerning the assessment of motivation constructs since we investigated patterns of change and not merely mean level changes. This methodological approach to studying the malleability of task value and self-efficacy increases our understanding of the nature of the changes in students' self efficacy and task value. Second, our study utilized a more rigorous approach to studying change patterns as we collected five waves of data of across the semester. Previous research examining changes within a semester was limited to fewer data points. More data points may have improved the reliability of the results. In fact, we attribute our observations of cubic trends to the collection of 5 waves of data. Future research concerning modeling patterns of change should strongly consider generating strategies to collect multiple waves of data and using growth curve modeling to more thoroughly assess whether experiences of change are shared by learners.

Finally, because we report fluctuations in students' motivations, we believe that educators can be more informed about motivational changes. Specifically, that change occurs; that task values and self-efficacy may change together; and that knowing the patterns of change can be used to make decisions about when to implement interventions (if necessary). Educational practices that have been found to enhance students' self-efficacy include educators providing motivational feedback and learning activities that allow for 
peer modeling [17, 20, 38].

Motivational feedback that encourages students to maintain their "efforts" and/or support students' capabilities to achieve helps students establish a sense confidence in knowing the demands and expectations on the achievement task. Peer modeling has also been found to be effective in enhancing student self-efficacy when students observe a similar peer competently achieve in a learning task. Providing students rationales for engaging in learning tasks has been a recommended strategy for enhancing positive values $[39,40]$. Rationales can give students insight into what is valued as important, useful, interesting, and/or costly. These are just a few strategies educators may find effective for their own classrooms; and because we found task value and self-efficacy to change with similar trajectories, educators may perhaps find that enhancing one motivational construct may trigger the enhancement of the other.

\section{Acknowledgements}

The authors of this paper contributed equally to the study.

\section{REFERENCES}

[1] L. Anderman, E. M. Anderman. Social Predictors of Changes in Students' Achievement Goal Orientations. Contemporary Educational Psychology, Vol. 24, No. 1, 21-37, 1999.

[2] G. V. Caprara, R. Fida, M. Vecchione, G. Del Bove, G. M. Vecchio, C. Babaranelli, A. Bandura. Longitudinal analysis of the role of perceived self-efficacy for self-regulated learning in academic continuance and achievement. Journal of Educational Psychology, Vol. 100, 525-534, 2008.

[3] N. Otis, F. E. Grouzet, L. G. Pelletier. Latent Motivational Change in an Academic Setting: A 3-Year Longitudinal Study. Journal Of Educational Psychology, Vol. 97, No. 2, 170-183, 2005.

[4] S. S. Shim, A. Ryan. Changes in self-efficacy, challenge avoidance, and intrinsic value in response to grades: The role of achievement goals. Journal of Experimental Education, Vol. 73, 333-349, 2005.

[5] M. Bong. Within-Grade Changes in Korean Girls' Motivation and Perceptions of the Learning Environment Across Domains and Achievement Levels. Journal of Educational Psychology, Vol. 97, No. 4, 656-672, 2005.

[6] C. Senko, J. M. Harackiewicz. Regulation of Achievement Goals: The Role of Competence Feedback. Journal Of Educational Psychology, Vol. 97, No. 3, 320-336, 2005.

[7] P. H. Winne, K. R. Muis, D. L. Jamieson-Noel. The stability of goal orientation as a function of feedback and calibration of achievement in a multi-assignment undergraduate course. American Psychological Association Convention, 2003.

[8] A. Zusho, P.R. Pintrich, B. Goppola. Skill and will: the role of motivation and cognition in the learning of college chemistry. International Journal of Science Education, Vol. 25, 1081,
2003.

[9] J. Corpus, M. S. McClintic-Gilbert, A. O. Hayenga. Within-year changes in children's intrinsic and extrinsic motivational orientations: Contextual predictors and academic outcomes. Contemporary Educational Psychology, Vol. 34, No. 2, 154-166, 2009.

[10] J. W. Fryer, A. J. Elliot. Stability and Change in Achievement Goals. Journal of Educational Psychology, Vol. 99, No. 4, 700-714, 2007

[11] K. R. Muis, O. V. Edwards. Examining the stability of achievement goal orientation. Contemporary Educational Psychology, Vol. 34, 265-277.

[12] A. Wigfield, J. S. Eccles. The development of competence beliefs and values from childhood through adolescence. In A. Wigfield and J. S. Eccles (Eds.), Development of achievement motivation. Academic Press, United States, 2002.

[13] Wigfield, J. S. Eccles. The development of achievement task values: a theoretical analysis. Developmental Review Vol. 12, 265-310, 1992.

[14] Q. Wang, E. Pomerantz. The motivational landscape of early adolescence in the United States and China: a longitudinal investigation. Child Development, Vol. 80, No. 4, 1272-1287, 2009.

[15] R. Chouinard, N. Roy. Changes in high-school students' competence beliefs, utility value and achievement goals in mathematics. British Journal of Educational Psychology, Vol. 78, No. 1, 31-50, 2008.

[16] J. S. Eccles, A. Wigfield. Motivational Beliefs, Values, and Goals. Annual Review of Psychology, Vol. 53, No. 1, 109, 2002.

[17] D. H. Schunk, P. R. Pintrich, J. L. Meece. Motivation in Education: Theory, Research and Applications. Pearson, United States, 2008

[18] A. Wigfield, J. S. Eccles. Expectancy-value theory of achievement motivation. Contemporary Educational Psychology, Vol. 25, 68-81, 2000.

[19] Bandura. Perceived Self-Efficacy in Cognitive Development and Functioning. Educational Psychologist, Vol. 28, No. 2, 117, 1993.

[20] E. Usher, F. Pajares. Self-efficacy for self-regulated learning: a validation study. Educational \& Psychological Measurement, Vol. 68, No. 3, 443-463, 2008.

[21] M. Bong, E. M. Skaalvik. Academic Self-Concept and Self-Efficacy: How Different Are They Really?. Educational Psychology Review, Vol. 15, No. 1, 1-40, 2003.

[22] J. S. Cole, D. A. Bergin, T. A. Whittaker. Predicting student achievement for low stakes tests with effort and task value. Contemporary Educational Psychology, Vol. 33, No. 4, 609-624, 2008.

[23] J. W. Atkinson. Motivational determinants of risk taking behavior. Psychological Review, Vol. 63, 359-372, 1957.

[24] M. Bong. Between- and Within-Domain Relations of Academic Motivation Among Middle and High School... Journal of Educational Psychology, Vol. 93, No. 1, 23, 2001. 
[25] F. W. Wicker, D. Hamman, J. H. Reed, E. J. McCann, J. E. Turner. Goal orientation, goal difficulty, and incentive values of academic goals. Psychological Reports, Vol. 96, 681-689, 2005.

[26] M. V. Covington. Making the grade: a self-worth perspective of motivation and school reform. Cambridge University Press, United States, 1992.

[27] P. R. Pintrich, D. A. Smith, T. Garcia, W. J. McKeachie. Reliability and predictive validity of the Motivated Strategies for Learning Questionnaire (MSLQ). Educational and Psychological measurement, Vol. 53, 801-813, 1993.

[28] T. Duncan, W. J. McKeachie. The Making of the Motivated Strategies for Learning Questionnaire. Educational Psychologist, Vol. 40, No. 2, 117-128, 2005.

[29] B.M. Byrne. Structural Equation Modeling with Mplus: Basic Concepts, Applications, and Programming (Multivariate Applications Series). Routledge, United States, 2012.

[30] X. Fan, X. Fan. Power of latent growth modeling for detecting linear growth: Number of measurements and comparison with other analytic approaches. Journal of Experimental Education, Vol. 73, No. 2, 121-139, 2005.

[31] Muthen, L. Muthen. Mplus User's Guide. Sixth Edition. Muthen \& Muthen, United States, 2010

[32] Muthén, K. Shedden. Finite mixture modeling with mixture outcomes using the EM algorithm. Biometrics, Vol. 55, 463-469, 1999.

[33] W. Herzog, A. Boomsma, S. Reinecke,. The model-size effect on traditional andmodified tests of covariance structures. Structural Equation Modeling, Vol. 14, No. 3, 361-390, 2007.

[34] W. Herzog, A. Boomsma. Small-sample robust estimators of noncentrality-based andincremental model fit. Structural Equation Modeling, Vol. 16, No. 1, 1-27, 2009.

[35] G. R. Hancock, R. O. Mueller (Eds.). The reviewer's guide to quantitative methods in the social sciences. Routledge, United States, 2010

[36] L. Hu, P. M. Bentler. Cutoff criteria for fit indexes in covariance structure analysis:Conventional criteria versus new alternatives. Structural Equation Modeling, Vol. 6, No. 1, $1-55,1999$.

[37] J. E. Jacobs, S. Lanza, D. Osgood, J.S. Eccles, A. Wigfield. Changes in Children's Self-Competence and Values: Gender and Domain Differences across Grades One through Twelve. Child Development, Vol. 73, No. 2, 509, 2002.

[38] L. Usher, F. Pajares. Sources of Self-Efficacy in School: Critical Review of the Literature and Future Directions. Review of Educational Research, Vol. 78, No. 4, 751-796, 2008 .

[39] M. L. Johnson, G. M. Sinatra. Use of Task-Value Instructional Inductions for Facilitating Engagement and Conceptual Change. Contemporary Educational Psychology, Vol. 38, No. 1, 51-63, 2013

[40] H. Jang. Supporting Students' Motivation, Engagement, and Learning During an Uninteresting Activity. Journal Of Educational Psychology, 100(4), 798-811, 2008. 